\title{
THE ESTIMATION OF CREATININE IN SERUM
}

\author{
BY \\ M. H. ROSCOE \\ From the Department of Medicine, Manchester University
}

(RECEIVED FOR PUBLICATION FEBRUARY 17,1953 )

\begin{abstract}
Although the clearance of endogenous creatinine as a measure of the glomerular filtration rate has been much criticized, it remains the only possible measure where repeated or continuous investigation is needed, and has already yielded much useful information. When we started to use it, however, it became apparent that while the estimation of creatinine in urine was satisfactory, that of plasma creatinine was not. The purpose of this work was therefore to establish a standard method of estimation simple enough for routine use. When this had been evolved it was used for a series of creatinine clearances, which were compared with simultaneous inulin clearances to see whether a reasonable agreement was apparent.

The basis of nearly all methods of estimation
\end{abstract} is the colour of the alkaline creatinine picrate (Jaffe, 1886) but it does not seem to have been realized how extremely sensitive this colour is to slight changes in media. The reaction was studied in detail by Bonsnes and Taussky (1945) and they outlined a procedure for urine which has not been questioned, but they only investigated a few blood filtrates and no serum or plasma. Some of the points they established are, however, important and may be summarized as follows. First the amount of coloured creatinine compound and the rate of its formation vary inversely with the amount of alkali present. Secondly, as a converse to this, the colour of the alkaline picrate, in which the creatinine compound is in solution and which is used as a blank in reading the colour, increases with the amount of alkali present. Thirdly, the colour response does not strictly follow De Beer's law, being proportional to concentration only in high dilutions. It follows from these findings that the composition of the alkaline picrate added to the creatinine solutions must be controlled, and this point has been studied, the most recent work being that of Lauson (1951). But it also follows that the reaction of the medium in which the creatinine is present may influence the colours of both the creatinine compound and the alkaline picrate by altering the proportions of alkali and picrate. This is not important when urine is the medium, as the estimation is made in dilute solutions approaching neutrality, but filtrates from blood plasma or serum may be sufficiently acid to have a significant effect.

The preparation of filtrates from blood has genera'ly been by the method of Folin (1919), using sodium tungstate and sulphuric acid. This involves a final dilution of 1 in 10 and is designed to give filtrates approaching neutrality. Brod and Sirota (1948) introduced two modifications, the dilution being reduced to 1 in 4 and the acid used being twice as strong, so that the filtrates are more acid. Another method is that of Popper, Mandel, and Mayer (1937) in which the proteins are precipitated with picric acid and $\mathrm{NaOH}$ alone added to the filtrate ; the values found by this method tend to be lower than with the tungstate method, and it was pointed out by Smith, Finkelstein, and Smith (1940), who used it, that the amounts of chromogenic substances estimated vary markedly when different methods of precipitation are used.

The matter is further complicated by the facts that the medium, even when neutral, may affect the colour, a possibility which does not appear to have been realized, and that plasma contains chromogens other than creatinine which give a colour with alkaline picrate.

The following points were investigated: (1) The colour of blank solutions of alkaline picrate ; (2) the colour of alkaline creatinine picrate in different media ; $(3)$ the time taken for the development of the colours of alkaline picrate, alkaline creatinine picrate, and picrate of other chromogens ; (4) the relationship between creatinine and inulin clearances.

\section{Methods}

In all cases the alkaline creatinine picrate was prepared by adding $2 \mathrm{ml}$. of $0.75 \mathrm{~N}$. NaOH and $2 \mathrm{ml}$. of saturated picric acid to $6 \mathrm{ml}$. of a solution containing $0.25-1.0 \mathrm{mg}$. of creatinine per $100 \mathrm{ml}$. In this range of concentration a linear colour response was obtained on a logarithmic scale. The density of the colour was measured with a Hilger Spekker photo- 
electric absorptiometer, using blue-green filters, No. 603 , readings being made against a blank, usually of water, $\mathrm{NaOH}$, and picric acid. The sensitivity of the apparatus was such that at creatinine concentrations of $0.5 \mathrm{mg}$. per $100 \mathrm{ml}$. the accuracy was not greater than $5 \%$.

For blood estimations serum was generally used, but heparinized plasma gave the same results. The proteins were precipitated by adding to 2 volumes of a serum dilution (usually 1 in 2) one part of sodium tungstate $5 \%$ (w.v.) and one part of either $0.33 \mathrm{~N}$. $\mathrm{H}_{2} \mathrm{SO}_{4}$ (precipitation A) or $0.66 \mathrm{~N}$. $\mathrm{H}_{2} \mathrm{SO}_{4}$ (precipitation B).

Creatinine clearances were calculated from the rate of creatinine excretion divided by the serum creatinine in nine normal subjects and in four patients with renal failure. Seven of the normals were from those investigated by Stanbury and Thomson (1952) in whom changes in filtration rate were induced by hyperventilation. Periods in the same subject when the filtration rate altered were considered separately, and in this way 27 different periods were obtained, the results in each being the mean of several urine samples.

Inulin was given either intravenously or as a subcutaneous depot. Frequent estimations of the serum inulin and creatinine concentrations were made. The inulin was estimated by the method described by Dick and Davies (1949).

\section{Results}

Colour of Alkaline Picrate.-This was investigated by reading the colour developed in various blanks, made by adding $\mathrm{NaOH}$ and picric acid to solutions of different $p \mathrm{H}$, against water alone, and also by comparing the results obtained when a standard alkaline creatinine picrate solution was read against these b'anks. The density of the colour of the alkaline picrate decreases as the acidity of the medium increases, so that the readings obtained from a standard alkaline creatinine picrate solution increase as more acid blanks are used. It follows that if the colour from creatinine in an acid solution is read against a blank made with water the result will be too low, because the alkaline picrate in the test solution will have less colour than in the blank. The error which may occur is shown in Fig. 1, where the changes in density of the alkaline picrate are shown as percentages of the colour observed when $\mathrm{NaOH}$ and picric acid are added to a $0.25 \mathrm{mg}$. per $100 \mathrm{ml}$. creatinine solution in water, a concentration similar to that found in normal sera diluted 1 in 4 . The points from which the response line is derived were obtained from buffer solutions at $p \mathrm{H} 6.0$ and 5.0 and 1 in 2 watery dilutions of precipitating reagents $\mathrm{A}$ and $\mathrm{B}$ with a $p \mathrm{H}$ of 2.2 and 1.0 respectively.

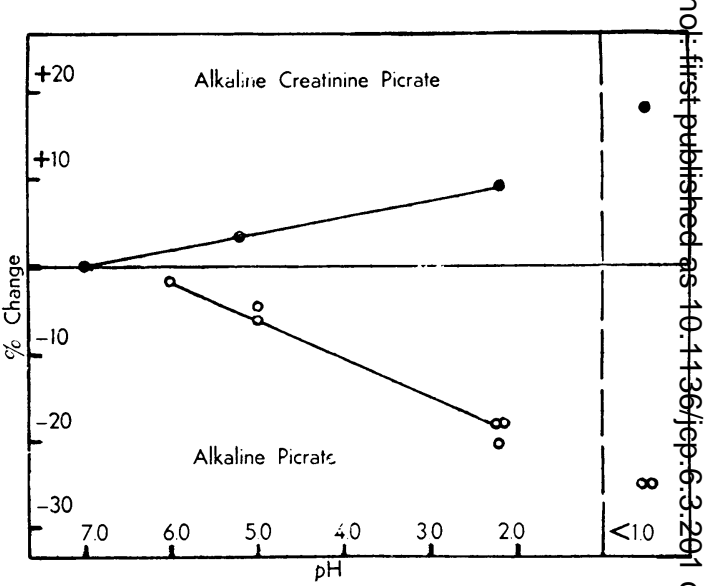

[IG. 1.-The effect of reaciion of the medium before adding $\mathrm{NaO}$ and picric acid on the colours of a!kaline picrate and alkaline creatinine picrate. The changes in colour densities of alkaline creatinine picrate are expressed as percentages of the co'our water, those of the a'kaline picrate as percentages of that $0.25 \mathrm{mg} 100 \mathrm{ml}$. creatinine in water.

Serum filtrates of 1 in 4 serum dilution fro $\vec{B}$ precipitation $\mathrm{A}$ have a $p \mathrm{H}$ of 4.8 to 5.7 , and at this reaction the colour of the a:kaline picrate is on $y$ slightly depressed, but filtrates of 1 in 4 seru cilution from precipitation $\mathrm{B}$ have a $p \mathrm{H}$ of 1.7 and here the colour depression is considerable. should also be noted that when serum is dilut more than 1 in 2 before the addition of the pre cipitating reagents the filtrate is more acid (Tabs I), so that appreciable depression of the alkaline p:crate colour will occur.

TABLE I

COLOUR DENSITY OF ALKALINE CREATININE PICRA욤 IN DIFFERENT MEDIA EXPRESSED AS PERCENTAG OF THE DENSITY IN WATER

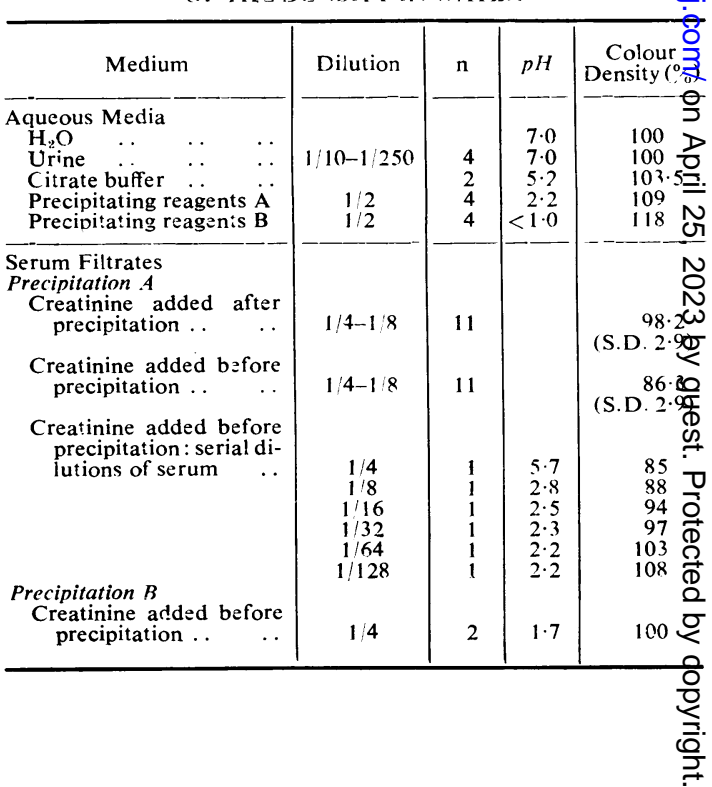


The Colour of Alkaline Creatinine Picrate in Different Media.-Here standard amounts of creatinine were added to different media, aliquots of which were used for blanks, so that variations in the colour of the alkaline picrate did not have to be considered.

In aqueous media (Tab'e I, Fig. 1) the colour increases with the acidity. Thus at $p \mathrm{H} 2.2$ there is $9 \%$ more colour than at $p \mathrm{H} \mathrm{7.0.} \mathrm{Creatinine} \mathrm{in}$ serum filtrates, of 1 in 4 dilution, from precipitation $\mathrm{B}$, which have a $p \mathrm{H}$ of 1.7 , would therefore be expected to give readings approximately $10 \%$ higher than the same concentration in water; but with similar filtrates from precipitation $A$, with a $p \mathrm{H}$ of about 5.0 , the difference should be less than $5 \%$.

However, when creatinine is added to serum and the protein is then precipitated with tungstic acid, the colour of the creatinine compound in the filtrate is less than that of an apparently similar concentration in water, or than that when the creatinine is added to the filtrate after precipitation. This is shown by the mean result of 11 sera in Table I. The concentrations of creatinine solution added to equal volumes of serum varied from 1 to $5 \mathrm{mg}$. per $100 \mathrm{ml}$. and the sera were of normal and of low protein content $(4.2 \mathrm{~g}$. per $100 \mathrm{ml}$. in two cases) yet the colour is very constantly $86.3 \%$ of that in water.

The colour depression is less when the serum is diluted further before protein precipitation, but if allowance is made for change in reaction it is seen still to be present. In Table I the colours from creatinine added to equal amounts of serial dilutions of a serum are shown. As the dilution becomes greater, the filtrate approaches in composition a 1 in 1 watery dilution of precipitating mixture $\mathbf{A}$, the serum constituents decreasing and the acidity of the medium increasing because there is less protein to neutralize the tungstic acid. At a serum dilution of 1 in 32 , the $p H$ is that of diluted precipitating mixture, but the colour is only that found in water, and it is not until a dilution of 1 in 128 that the colour is that found in the diluted precipitating mixture.

Table II shows the resu't of diluting filtrates from sera to which creatinine has been added. In order to keep the readings on the linear part of the scale, increasing amounts of creatinine were added to aliquots of a serum and increasing dilutions of filtrate made so that they contained 0.3125 and $0.625 \mathrm{mg}$. per $100 \mathrm{ml}$. at four different serum dilutions. As the amount of serum filtrate in the final medium becomes less, the same concentration of creatinine gives more colour. This cannot be due
TABLE II

COLOUR DENSITY OF ALKALINE CREATININE PICRATE ADDED TO SERUM BEFORE PROTEIN PRECIPITATION (METHOD A) AND EFFECT OF FILTRATE DILUTION

\begin{tabular}{|c|c|c|c|c|c|}
\hline \multirow{2}{*}{$\begin{array}{c}\text { Creatinine } \\
\text { Added to } \\
\text { Equal Vol. } \\
\text { Serum } \\
(\mathrm{mg} . / 100 \mathrm{ml} .)\end{array}$} & \multirow{2}{*}{$\begin{array}{c}\text { Dilu- } \\
\text { tion of } \\
\text { Fi!-- } \\
\text { trate }\end{array}$} & \multirow{2}{*}{$\begin{array}{c}p \mathrm{H} \\
\text { of } \\
\text { Diluted } \\
\text { Filtrates }\end{array}$} & \multicolumn{2}{|c|}{ Co'our Densi:y* } & \multirow{2}{*}{$\begin{array}{c}\text { Final } \\
\text { Serum } \\
\text { Dilution }\end{array}$} \\
\hline & & & $\begin{array}{c}0.3125 \\
(\mathrm{mg} ! 100 \mathrm{ml} .)\end{array}$ & $(\mathrm{mg} / 100 \mathrm{ml}$.) & \\
\hline 1.25 & 0 & $5 \cdot 2$ & 82 & 158 & 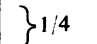 \\
\hline $2 \cdot 5$ & $1 / 2$ & $5 \cdot 6$ & 88 & 180 & \\
\hline 5.0 & $1 / 4$ & $6 \cdot 1$ & 102 & 186 & $1 / 16$ \\
\hline $\begin{array}{l}10 \cdot 0 \\
20 \cdot 0\end{array}$ & $1 / 8$ & $6 \cdot 6$ & 98 & 194 & ?. \\
\hline
\end{tabular}

*\% of the colour of $0.3125\left(\mathrm{mg} / 100 \mathrm{ml}\right.$.) in $\mathrm{H}_{2} \mathrm{U}$.

to the reaction of the medium, which approaches neutrality with increasing dilution.

Tab'e II also shows that the colour from creatinine added to serum before precipitation is approximately proportional to the amount added, since at each serum dilution doubling the quantity produces twice the colour. This was also seen in three other cases with 1 in 4 serum dilutions, where the double amounts gave colour densities of 193 , 200 , and $205 \%$ of the densities of the single amounts.

The Rate of Colour Development.-The colour of the alkaline picrate develops quickly, being complete in five minutes.

In Figs. 2 and 3 are shown the densities, expressed as percentages of the final density due to creatinine, of various solutions containing creatinine at intervals after the addition of picric acid and $\mathrm{NaOH}$. In aqueous solutions (Fig. 2) the speed of the reaction decreases with increasing acidity,

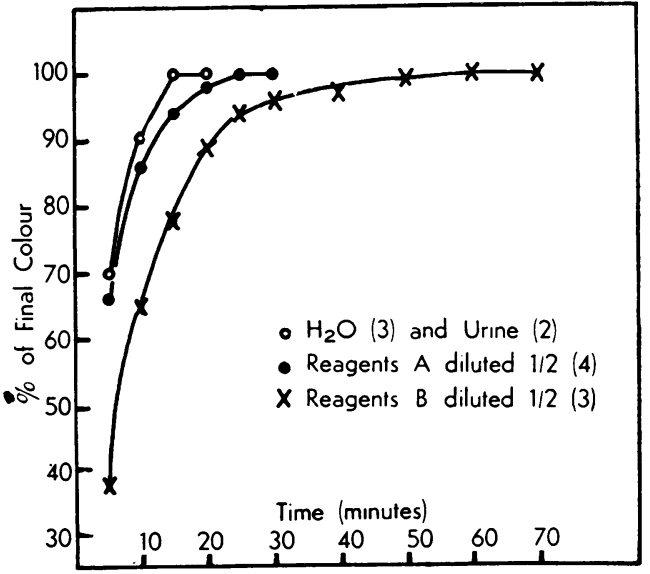

FIG. 2.-The rate of colour development of alkaline creatinine picrate in aqueous media. The number of results from which the points are derived are given in parentheses. 


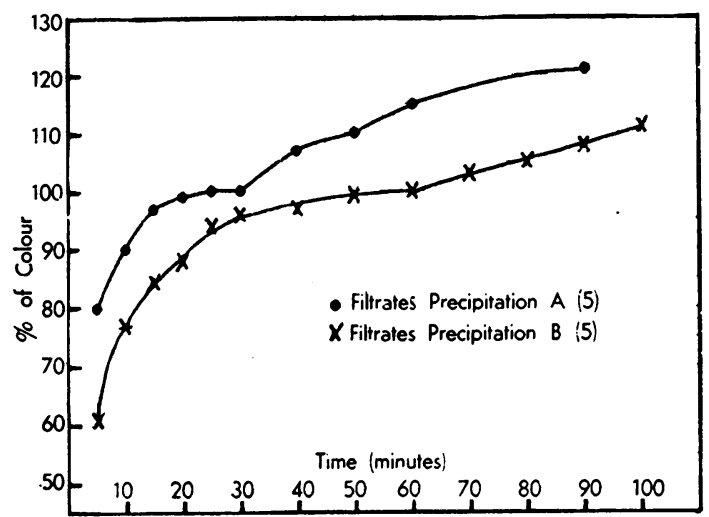

FIG. 3.- The rate of colour development of alkaline creatinine picrate and other chromogens in serum filtrates. The colours are expressed as percentages of the density at $\mathbf{3 0}$ minutes for precipitation $A$, and that at 60 minutes for precipitation $B$. The number of results from which the points are derived are given in parentheres.

being comp'ete at 15 minutes in water or urine, 25 minutes in diluted reagents $\mathrm{A}(p \mathrm{H} \mathrm{2.2})$, and 60 minutes in diluted reagents $\mathrm{B}(p \mathrm{H} \mathrm{1.0)}$. The colour in serum filtrates (Fig. 3), however, increases as long as they are watched. If the rate is dependent on the reaction in filtrates from precipitation $A$ with a $p \mathrm{H}$ of 5.2 to 5.4 the creatinine colour may be expected to be complete by 25 minutes, and there is in fact a flattening of the curves at this point (Fig. 3), so it would seem that the colour developing after this is due to other chromogens. Similarly the creatinine colour in filtrates from precipitation B may be expected to be complete by 60 minutes and the colour after this is probably due to non-creatinine chromogens. Thus, in order to avoid over-estimation of the creatinine colour it should be read in preparations from reagents $A$ at 25 to 30 minutes, and in those from reagent $B$ at 60 minutes.

Five filtrates from precipitation $\mathbf{A}$ increased by 12 to $18.5 \%$ (mean 15 ) from 30 to 60 minutes after mixing, and by 16 to $33 \%$ (mean 21 ) from 30 to 90 minutes. Five filtrates from precipitation B increased by a mean of $14 \%$ from 60 to 120 minutes. If this colour is due to non-creatinine chromogen it is probable that so also is some of the original colour, and it is tempting to make a deduction proportional to the later increase in order to find the colour due to creatinine alone. The later colour increases are, however, discontinuous, suggesting that they are due to a number of different chromogens darkening at different rates and they are too small for accurate calculations to be made from them.

In sera from normal subjects there is no obvious relationship between the amount of creatinine present and the colour developing after com pletion of the creatinine reaction, but there is $\overrightarrow{\vec{\partial}}$ slight tendency for less colour to develop whew the creatinine content is in the upper ranges of normal. In the sera from patients with raise plasma creatinine levels there is seldom an $\overrightarrow{8}$ evidence that non-creatinine chromogen is presentw The estimation in these cases has to be carried ouf on diluted serum filtrates, and in 13 such samples? where the final dilution was 1 in 8 to 1 in 32 as. compared with the usual 1 in 4 , only two samples showed any increase in colour after 30 minutes (precipitation A). Chromogen may still have beeb present, though not in amounts which showed aftew dilution, but it is clear that the proportion of non creatinine chromogen to creatinine had fallen. It therefore seems that there is less likelihood of over-estimation of creatinine when there is much present in the plasma than when there is little.

Comparison of Creatinine and Inulin Clearo ances.-These creatinine clearances were calculated using a standard method of serum creatinine estimation adopted as a result of the foregoing results, and given at the end of this paper.

In Fig. 4 the creatinine and inulin clearance found in 27 periods are compared. The creatinine clearances in normal subjects (inulin clearance्ల greater than $70 \mathrm{ml} . / \mathrm{min}$.) are with one exceptio® lower than the inulin clearances, the relationship $\vec{B}$ being expressed by the regression equation:

$$
\mathrm{C}_{\mathrm{Cr}}=0.76 \mathrm{C}_{\mathrm{In}}+7.6
$$

The regression line to this equation is drawn in the figure with the standard deviation from the line, which is 13.4 .

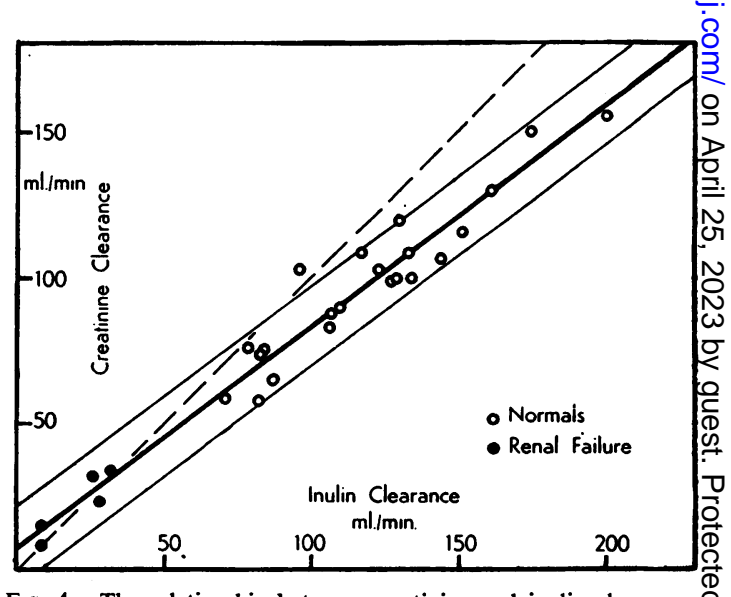

FIG. 4.-The relationship between creatinine and inulin c'earances? The broken line shows the expected relationship of $\mathrm{CO}=\mathrm{CIn}, \mathrm{O}$ the thick continuous line that found in normal subjects; and the thin lines the standard deviation from this. 
The creatinine clearances in the five periods from four patients with low filtration rates differ little from the inulin clearances, and at the same time they are similar to the expected values calculated from the regression equation obtained from the normals.

Thus at all levels of glomerular filtration there is a reasonably constant relationship between the creatinine and inulin clearances of such a nature that, whereas at normal clearances the creatinine clearance is less than the inulin clearance (by about $16 \mathrm{ml}$. at $100 \mathrm{ml}$. per min.), the difference decreases with falling clearances, so that at $30 \mathrm{ml}$. per min. the creatinine clearance is equal to the inulin clearance.

\section{Discussion}

It is apparent from these results that the estimation of serum creatinine will be unreliable unless the conditions are carefully controlled. Values which are too low may be obtained either because it is not realized that the colour of alkaline creatinine picrate may be depressed after protein precipitation or because acid solutions are used which depress the colour of the alkaline picrate. Values which are too high may be obtained because filtrates from preparations made with acid precipitating mixtures or with filtrates from diluted serum are used. Inaccuracies may be introduced by reading the colour before it is fully developed or later when colour from extraneous chromogen has increased. And finally an unknown amount of the colour is probably due to extraneous chromogen. In previous work on the subject there is a surprising lack of evidence as to whether these points were considered, so that it is not possible to see whether the results may have been affected.

The fact that creatinine added before protein precipitation gives less colour than when it is added afterwards has been noted by several workers, but they have all assumed that this was due to loss of creatinine during the precipitation. This led. Brod and Sirota (1948) to add more acid to their precipitating mixture, which gave a highly acid filtrate in which the creatinine developed the same colour as in water, but which has serious disadvantages. Camara, Arn, Reimer, and Newburgh (1951) found that 96 and $95 \%$ recoveries were obtained when creatinine was added to filtrates from sera diluted 1 in 10 and 1 in 4 respectively, while when it was added before precipitation recovery was only 88 and $78 \%$ respectively. Since higher dilutions of serum give more acid filtrates, more colour with the 1 in 10 dilutions than with those of 1 in 4 is understandable. Lauson (1951), however, found no colour loss with 1 in 5 serum dilutions so long as the serum proteins were normal, but a decrease, approaching $10 \%$, if they were low. This decrease was proportional to the fall in protein concentration or acidity of the filtrate. This result is the opposite of that found here, where serum with a low protein content gave the same results as that with a normal protein content, and reduction of the protein to be precipitated, by dilution of normal serum, resulted in increased colour.

The present results suggest that creatinine is not lost during protein precipitation by tungstic acid, but that the alkaline creatinine picrate formed in these circumstances is modified so that it gives less colour. This appears a better explanation of the fact that at any given serum dilution the colour is proportional to the creatinine originally present than the assumption that a constant proportion of the original creatinine is lost. The latter theory also is not supported by the facts, for in the experiment shown in Table II the colours given by the two dilutions of any one filtrate are not proportional, that in the higher being greater than that in the lower. This suggests that during precipitation the creatinine is altered, so that its alkaline picrate gives less colour, but that if the filtrate is sufficiently diluted this process is reversed.

The methods of estimating true creatinine, as distinct from total chromogen, have not been investigated here, as it was felt that they are not suitable for routine work. Two procedures are available: the first adsorption of creatinine on Fuller's earth and either estimation by difference or elution and estimation (Gaebler and Keltch, 1928 ; Hayman, Halsted and Seyler, 1933 ; Borsook, 1935 ; Hare and Hare, 1949; Lauson, 1951). The second involves destruction of true creatinine by a specific enzyme (Miller and Dubos, 1937 ; Allinson, 1945). By both these methods the non-creatinine chromogen is found to be about $20 \%$ of the total chromogen in serum or plasma from normal subjects, but evidence as to the proportion in plasma from patients with nitrogen retention is scanty and conflicting. Miller and Dubos (1937) and Brod (1949) found a higher proportion than in normals, while Hare and Hare (1949) and Miller and Miller (1951) found a lower proportion, and Lauson (1951) found that the colour from non-creatinine chromogen was suppressed by increasing concentrations of creatinine. The present work agrees with the results of the last authors in that the proportion of non-creatinine chromogen to creatinine appeared to decrease as the creatinine content rose.

Lauson (1951) pointed out the desirability of reading colours as soon as the true creatinine 
colour has developed. He also considered that it might be possible to correct for extraneous colour by extrapolating the later curve of colour increase to zero. This was considered in the present work, but it was not felt that it was sufficiently accurate to be justified.

When in the past creatinine clearances, obtained using various methods of plasma creatinine estimation, were compared with inulin clearances, one of the most disconcerting things was that even in the hands of the same workers they not only varied greatly but also in normal cases were sometimes greater and sometimes less, while in cases of renal failure they were generally greater (Shannon, 1935 ; Miller and Winkler, 1938 ; Steinitz and Türkand, 1940 ; Smith et al., 1940 ; Brod and Sirota, 1948 ; Hare and Hare, 1949 ; Miller, Leaf, Mamby, and Miller, 1952). Since the creatinine clearances were often greater than the inulin clearances it was not possible to attribute the differences entirely to the presence of non-creatinine chromogen, which, by fallaciously increasing plasma values, would lower the clearances. The results are more easy to understand, however, when the number of possible errors in plasma creatinine estimation, some leading to too high values and some to too low, are realized, and when the estimation in serum was standardized. in the present work no creatinine clearances significantly greater than inulin clearances were found and the majority were lower. It is therefore very probable that the difference here is due to the overestimation of the serum creatinine level, and this is borne out by the amount of the difference, which in normal subjects is about $15 \%$, which would occur if $20 \%$ of the chromogen were not creatinine, the figure found by other workers by direct estimation. The fact that when the serum creatinine level is high the creatinine clearance is similar to the inulin clearance is explained by the finding that under these circumstances non-creatinine chromogen is present in smaller proportions or its colour is suppressed so that this error is slight or absent.

It is possible to calculate corrected creatinine clearances from the expression relating creatinine and inulin clearances found here, but it is not felt that this relationship was based on sufficient data and the variations were such as to make it appear inadvisable. It seems better to consider at present that the creatinine clearance gives an approximate measurement of the glomerular filtration rate, rather too low at normal levels, more accurate at lower levels.

In calculating creatinine clearances it should be remembered that the serum creatinine level is not constant. Sirota, Baldwin, and Villarreal (1950) investigated diurnal variations and found changes? up to $17 \%$, and a normal subject investigated in this $\vec{F}$ laboratory showed a nocturnal increase of from? $1.30 \mathrm{mg}$. per $100 \mathrm{ml}$. to $1.55 \mathrm{mg}$. per $100 \mathrm{ml}$., of $19 \%$.

\section{Summary}

The estimation by the Jaffe reaction of creatinine in serum, after precipitation of the proteins with? tungstic acid, was investigated.

The colour density of the alkaline picrate in which the alkaline creatinine picrate is in solution decreases with increasing acidity. This may lead toํำ underestimation of creatinine when acid serums filtrates are used.

The colour density of the alkaline creatining picrate increases with increasing acidity, so that it is greater in more acid serum filtrates.

Creatinine added to serum and subjected to protein precipitation gives less colour that creatinine added to filtrates. This appears to be due, not to loss of creatinine, but to a change in the creatinine, which is reversed if the filtrates areo sufficiently diluted.

The time for full development of the alkaline creatinine picrate colour increases with increasing acidity of the medium. Normal serum filtrates owing to the presence of extraneous chromogens darken indefinitely, but filtrates from serum with a high natural creatinine content seldom show this effect.

A standard method of estimating creatinine serum is described in an Appendix.

Using this method, creatinine clearances in series of normals were slightly less than simuf taneous inulin clearances. In patients with rendi failure the creatinine and inulin clearances wexe. very similar.

\section{A P P E N D I X}

\section{Standard Method of Serum Creatinine Estimation}

Reagents.-The following are required : $5 \%$ (w.w sodium tungstate; $0.33 \mathrm{~N}$. $\mathrm{H}_{2} \mathrm{SO}_{4} ; 0.75 \mathrm{~N}$. NaOH; saturated solution of picric acid; stock creatinires standard solution containing $0.5 \mathrm{~g}$. creatinine in 11 . 0 $0.1 \mathrm{~N}$. $\mathrm{HCl}$.

Precipitation of Protein.-Two $3 \mathrm{ml}$. samples serum are measured into centrifuge tubes. To the first (X) is added $3 \mathrm{ml}$. of distilled water and to the second (S) $3 \mathrm{ml}$. of a $20 \mathrm{mg} . \%$ creatinine solution prepared from the stock solution by dilution with distilled water. The solutions are mixed, and to eaç $3 \mathrm{ml}$. of $5 \%$ sodium tungstate is added; the resulting solution is mixed again and $3 \mathrm{ml}$. of $0.33 \mathrm{~N}$. $\mathrm{H}_{2} \mathrm{~S}$ added. The tubes are allowed to stand for $10 \mathrm{mit}$. and then centrifuged. The supernatant fluid is filtereg 
Preparation and Estimation of Alkaline Creatinine Picrate.-To $6 \mathrm{ml}$. samples of protein-free fluid from $X$ and $S$ and to $6 \mathrm{ml}$. of distilled water (B) $4 \mathrm{ml}$. of a fresh mixture of equal parts of $0.75 \mathrm{~N}$. $\mathrm{NaOH}$ and saturated picric acid is added, mixed, and allowed to stand. After 25 to 30 minutes the densities are measured with a Spekker absorptiometer, using bluegreen filters, No. 603, $\mathrm{X}$ being read against the blank $B$ and the standard $S$ against $X$. Then, since the $2.0 \mathrm{mg} . \%$ standard has been diluted 1 in 4 :

$$
\text { Creatinine }=\left\{\frac{\text { Reading of } X}{\text { Reading of } S} \times \frac{2.0}{4}\right\} \mathrm{mg} . \%
$$

If there is not sufficient serum for the preparation of a standard in serum, a standard in water is prepared (S') with $6 \mathrm{ml}$. of $0.5 \mathrm{mg} . \%$ creatinine solution and $4 \mathrm{ml}$. of $\mathrm{NaOH}$ and picric acid. This is read against $B$. A correction must then be made for the fact that in serum filtrates creatinine has approximately $90 \%$ of the density of that in water. Thus:

$$
\text { Creatinine }=\left\{\frac{\text { Reading of } X}{\text { Reading of } S^{\prime}} \times 0.5 \times 1.11\right\} \mathrm{mg} . \%
$$

Sera with High Creatinine Concentrates.-If the concentration is greater than $3.0 \mathrm{mg} . \%$ the serum filtrate must be diluted. Appropriately higher concen- trations of creatinine solution must be added to the serum used for preparation of the standard, and the filtrate from this diluted in the same way.

\section{REFERENCES}

Allinson, M. J. C. (1945). J. biol. Chem., 157, 169.

Bllinson, M. J. C. (1945). J. biol. Chem., 157, 169.

Bonsnes, R. W., and Taussky, H. H.

Brod, J. (1949). Klinická fysiologie a pathologie Ledvin. Praha. and Sirota, J. H. (1948). J. clin. Invest., 27, 645.

Camara, A. A., Arn, K. D., Reimer, A., and Newburgh, L. H. (1951). J. Lab. clin. Med., 37, 743.

Dick, A.. and Davies, C. E. (1949). Journal of Clinical Pathology, 2, 67.

Folin, O., and Wu, H. (1919). J. biol. Chem., 38, 81 .

Gaebler, O. H., and Keltch, A. K. (1928). Ibid., 76, 337.

Hare, R. S., and Hare, K. (1949). Fed. Proc., 8, 68.

Hayman, J. M., Haisted, J. A., and Seyler, L. E. (1933). J. clin. Invest , 12, 861

Jaffe, M. (1886) Z physiol. Chem., 10, 391.

Lauson, H. D. (1951). J. appl. Physiol., 4, 227.

Miller, B. F., and Dubos, R. (1937). J. biol. Chem., 121, 447, 457. Leaf, A., Mamby, A. R., and Miller, Z. (1952). J. clin. Invest., 31, 309 .

- and Winkler, A. W. (1938). Ibid., 17, 31

Miller, Z and Miller, B. F. (1951). Proc. Soc. exp. Biol., 78, 471.

Popper, H. Mandel, E. and Mayer, H. (1937). Biochem. Z . 291, 354.

Sirota, J. H., Baldwin, D. S., and Villarreal, H. (1950). J. clin. Invest., 29, 187.

Shannon, J. A. (1935). Ibid., 14, 403.

Smith, W. W., Finkelstein, N.. and Smith, H. W. (1940). J. biol. Chem. 135, 231.

Stanbury, S. W., and Thomson, A. E. (1952). Clin. Sci., 11, 357.

Steinitz, K., and Türkand, H. (1940). J. clin. Invest., 19, 285. 